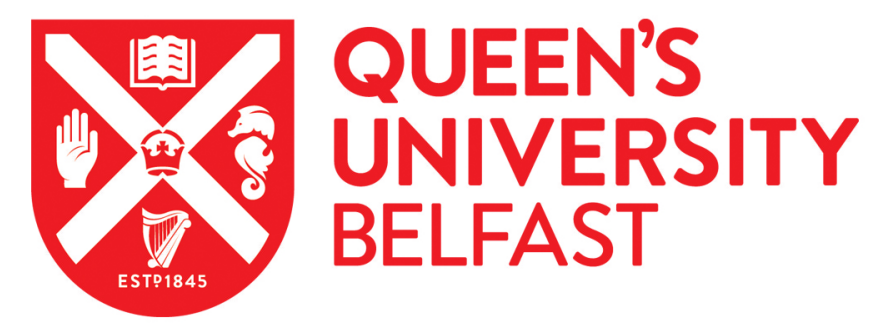

\title{
Spin State Solvomorphism in a Series of Rare S = 1 Manganese(III) Complexes
}

Barker, A., Kelly, C., Kühne, I. A., Hill, S., Krzystek, J., Wix, P., Esien, K., Felton, S., Müller-Bunz, H., \& Morgan, G. G. (2019). Spin State Solvomorphism in a Series of Rare $S=1$ Manganese(III) Complexes. Dalton Transactions. https://doi.org/10.1039/C9DT02476J

Published in:

Dalton Transactions

Document Version:

Peer reviewed version

Queen's University Belfast - Research Portal:

Link to publication record in Queen's University Belfast Research Portal

Publisher rights

(C) 2019 Dalton Transactions.

This work is made available online in accordance with the publisher's policies. Please refer to any applicable terms of use of the publisher.

\section{General rights}

Copyright for the publications made accessible via the Queen's University Belfast Research Portal is retained by the author(s) and / or other copyright owners and it is a condition of accessing these publications that users recognise and abide by the legal requirements associated with these rights.

Take down policy

The Research Portal is Queen's institutional repository that provides access to Queen's research output. Every effort has been made to ensure that content in the Research Portal does not infringe any person's rights, or applicable UK laws. If you discover content in the Research Portal that you believe breaches copyright or violates any law, please contact openaccess@qub.ac.uk. 


\title{
ARTICLE
}

Received 00th January 20xx

Accepted 00th January 20xx

DOI: $10.1039 / \times 0 \times x 00000 x$

\section{Spin State Solvomorphism in a Series of Rare S = 1 Manganese(III) Complexes}

\author{
Andrew Barker, ${ }^{a}+$ Conor T. Kelly, ${ }^{a}+$ Irina A. Kühne, ${ }^{a}$ Stephen Hill, ${ }^{b, c}$ J. Krzystek, ${ }^{b}$ Paul Wix, ${ }^{d}$ Kane
} Esien, ${ }^{\mathrm{e}}$ Solveig Felton, ${ }^{\text {,f }}$ Helge Müller-Bunz ${ }^{\mathrm{a}}$ and Grace G. Morgan*a

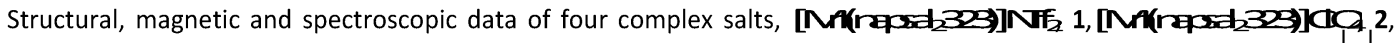

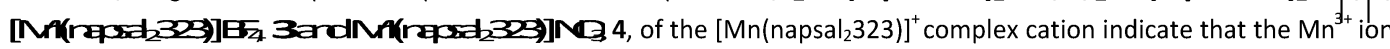
is stabilized in the rare $S=1$ spin triplet form in this ligand sphere. Zero-field splitting values of $D=+19.6 \mathrm{~cm}^{-1}$ and $=$ $2.02 \mathrm{~cm}^{-1}$ for complex 1 were obtained by High Field Electron Paramagnetic Resonance (HFEPR) measurements conducted over a range of frequencies and field strengths. Structural and magnetic data also indicate that co-crystallization of complexes $\mathbf{2}$ and $\mathbf{3}$ with 0.5 equivalents of ethanol yields the high spin $\mathrm{S}=2$ forms of the perchlorate and tetrafluoroborate

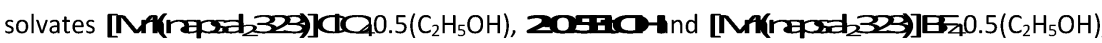

30sico-1

\section{Introduction}

Manipulation of spin states in transition metal elements offers an interesting route to spintronic applications. ${ }^{1-5}$ Many $d^{n}$ configurations can have more than one arrangement of spins, fully unpaired being the most common, Table 1 , but alternative fully paired or partially paired configurations are also possible in $d^{4}-d^{7}$ ions. Thermal switching between high spin (HS) and low spin (LS) forms is well known and much studied in $\mathrm{Fe}^{2+}$ and $\mathrm{Fe}^{3+}$ complexes. Transitions between the intermediate spin (IS) and either the $\mathrm{HS}^{6}$ or $\mathrm{LS}^{7}$ state in $\mathrm{Fe}^{3+}$ are also known but are much less common. A smaller number of $\mathrm{Co}^{2+}$ complexes also show thermal spin state switching, in this case always between the fully paired and fully unpaired arrangements, Table $1^{8,9}$ Thermal spin state switching is also now relatively well established in some $\mathrm{Mn}^{3+}$ complexes where the transition is always between the $S=1$ IS and the $S=2 \mathrm{HS}$ states. $^{10-19}$

Table 1. High Spin (HS), Intermediate Spin (IS) and Low Spin (LS) S values for $d^{4}-d^{7}$ configurations.

\begin{tabular}{llll}
\hline $\mathbf{d}^{4}$ & $\mathbf{d}^{5}$ & $\mathbf{d}^{6}$ & $\mathrm{~d}^{7}$ \\
$\mathrm{Mn}^{3+}, \mathrm{Cr}^{2+}$ & $\mathrm{Fe}^{3+}, \mathrm{Mn}^{2+}$ & $\mathrm{Fe}^{2+}, \mathrm{Co}^{3+}$ & $\mathrm{Co}^{2+}$ \\
\hline $\mathrm{HS}, \mathrm{S}=2$ & $\mathrm{HS}, \mathrm{S}=5 / 2$ & $\mathrm{HS}, \mathrm{S}=2$ & $\mathrm{HS}, \mathrm{S}=3 / 2$ \\
$\mathrm{IS}, \mathrm{S}=1$ & $\mathrm{IS}, \mathrm{S}=3 / 2$ & $\mathrm{IS}, \mathrm{S}=1$ & - \\
$\mathrm{LS}, \mathrm{S}=0$ & $\mathrm{LS}, \mathrm{S}=1 / 2$ & $\mathrm{LS}, \mathrm{S}=0$ & $\mathrm{LS}, \mathrm{S}=1 / 2$ \\
\hline
\end{tabular}

a. School of Chemistry, University College Dublin (UCD), Belfield, Dublin 4, Ireland.

${ }^{b .}$ National High Magnetic Field Laboratory, Florida State University, Tallahassee, FL 32310, USA.

Department of Physics, Florida State University, Tallahassee, FL 32306, USA.

d. School of Chemistry \& CRANN Institute, Trinity College Dublin, University of

Dublin, College Green, Dublin 2, Ireland.

e. School of Mathematics and Physics, Queen's University Belfast, Belfast, UK.

f. Centre for Nanostructured Media (CNM), Queen's University Belfast, Belfast, UK.

+ These authors contributed equally to the work.

Electronic Supplementary Information (ESI) available: [details of any supplementary information available should be included here]. See DOI: $10.1039 / x 0 x x 00000 x$
However, although thermal switching between spin triplet and quintet states is possible in $\mathrm{Mn}^{3+}$, by far the majority of reported molecular and solid state compounds with this ion are HS i.e. they obey Hund's first rule of maximum spin multiplicity. This makes the $\mathrm{S}=1$ state something of a chemical and magnetic rarity with less than twenty reported $\mathrm{Mn}^{3+}$ complexes in the spin triplet form at room temperature. These $S=1$ examples can be broadly sorted into four categories: $\left[\mathrm{Mn}(\mathrm{CN})_{6}\right]^{3-}$ complexes with different counter cations; $^{20-24}$ porphyrin ${ }^{25-28}$ or cyclam ${ }^{29}$ type ligands with axially coordinated ligands such as cyanide; poly(pyrazolyl)borate type complexes; ${ }^{30-33}$ and a smattering of others which are less easily categorized including those with tris(quinone) oximate ligands, ${ }^{34}$ or carboxylate donors. ${ }^{35}$ The triplet form of $\mathrm{Mn}^{3+}$ thus represents a less-prevalent building block in molecular magnetism and one which is worthy of further investigation, both as a potential single ion magnet (SIM), or as a starting point for thermal or non-thermal spin state switching to the quintet form at or above room temperature.

We now report four new $\mathrm{Mn}^{3+}$ compounds, all salts of the $[\mathrm{Mn}(\text { napsal } 2323)]^{+}$complex cation, which are fully or predominantly in the rare $S=1$ state at room temperature. The ligand napsal ${ }_{2} 323$ is a Schiff base resulting from condensation of 1,2-bis(3aminopropylamino)ethane with 2-hydroxy-1-naphthaldehyde which we have abbreviated as napsal 2323 to indicate the 323 alkyl connectivity in the starting tetraamine and the presence of a napthol donor. $\left[\mathrm{Mn}\left(\text { napsal }_{2} 323\right)\right]^{+}$belongs to the $[\mathrm{Mn}(\mathrm{R}$ $\left.\left.\mathrm{sal}_{2} 323\right)\right]^{+}$series of Schiff base complexes of which other members have been shown to exhibit thermal spin crossover. ${ }^{11-16}$ However, with previously reported ligands in the series, $\mathrm{Mn}^{3+}$ is almost always in the HS state at room temperature or shows a variation of spin state for the same complex cation with different counterions. In 
contrast the larger naphthol donor groups in the ligand used here stabilize the $[\mathrm{Mn}(\text { napsal } 2323)]^{+}$cation in the $\mathrm{S}=1$ state in all the (solvate-free) crystalline lattices which were examined. Cocrystallization with ethanol however disrupts the packing and allows access to the $S=2$ state in the perchlorate and tetrafluoroborate cases. This illustrates that solvomorphs of the $\left[\mathrm{Mn}\left(\text { napsal }{ }_{2} 323\right)\right]^{+}$complex can stabilize different internal electronic arrangements and hence different magnetic states.

\section{Results and Discussion}

\section{Synthesis}

Preparation of the bistriflimide $\left(\mathrm{NTf}_{2}{ }^{-}\right)$, perchlorate $\left(\mathrm{ClO}_{4}{ }^{-}\right)$, tetrafluoroborate $\left(\mathrm{BF}_{4}{ }^{-}\right)$and nitrate $\left(\mathrm{NO}_{3}{ }^{-}\right)$salts of $\left[\mathrm{Mn}\left(\text { napsal }_{2} 323\right)\right]^{+}$was achieved in a one-pot reaction, Scheme 1 , where different exchange salts $(\mathrm{AX})$ were used to prepare four different salts of the complex cation, as well as solvates of two of

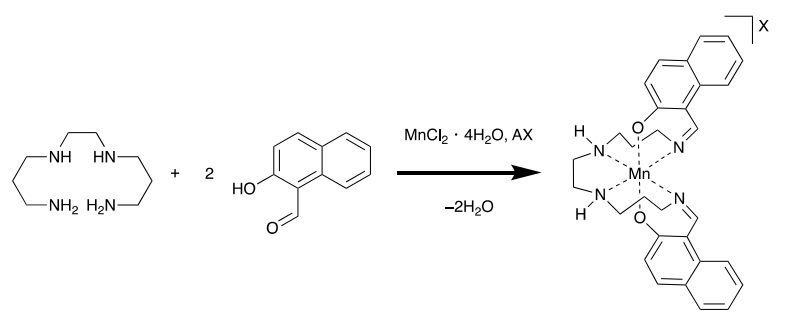

these salts, those of $\mathbf{2}$ and $\mathbf{3}$, Scheme 1.

\begin{tabular}{|c|c|}
\hline conplex & Melesilarfanda \\
\hline 1 & {$\left[\mathrm{Mr}\left(\mathrm{r}_{\mathrm{A}} \mathrm{d}_{2} 32\right)\right] \mathrm{NF}_{2}$} \\
\hline 2 & {$\left[\mathrm{Mn}\left(\mathrm{rag}_{2} 323\right)\right] \mathrm{Ca}$} \\
\hline 20.5EtOH & {$\left[\mathrm{Mr}\left(\mathrm{rag}_{2} 323\right)\right] \mathrm{Ca} 0.5\left(\mathrm{C}_{2} \mathrm{H}_{5} \mathrm{OH}\right)$} \\
\hline 3 & 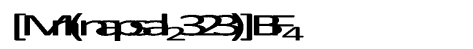 \\
\hline 30.5EtOH & {$\left[\mathrm{Mr}\left(\mathrm{rag}_{2} 323\right)\right] \mathrm{B}_{4} 0.5\left(\mathrm{C}_{2} \mathrm{H}_{5} \mathrm{OH}\right)$} \\
\hline 4 & 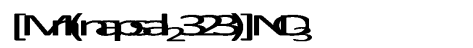 \\
\hline
\end{tabular}

Strene 1 Syrtheis of complees $1-4$ ardschetes $20.5 \mathrm{EtOH}$ and

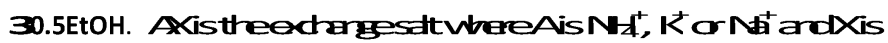
$\mathrm{NF}_{2}(1), \mathrm{CC}_{4}(2), \mathrm{EF}_{4}$ (3) ONO (4).

\section{Magnetic Characterisation of Unsolvated $(S=1)$ Complexes}

Variable temperature magnetic susceptibility of polycrystalline samples of unsolvated complexes $\mathbf{1 - 4}$ was recorded on a Quantum Design MPMS XL SQUID between $2 \mathrm{~K}$ and 300 , Figure 1.
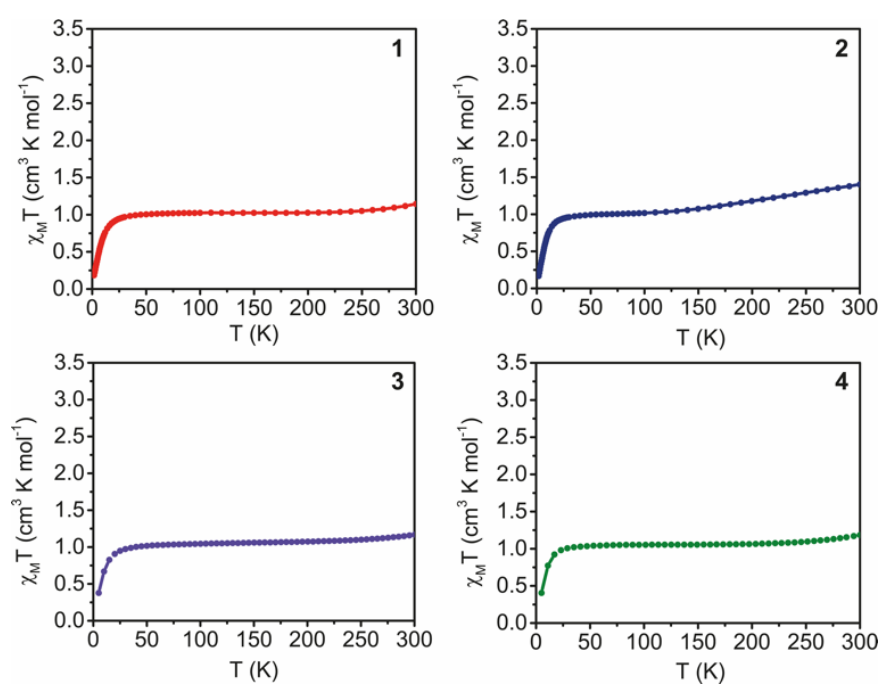

Figure 1. Plots of $\chi_{M} T$ vs $T$ for complexes $1-4$ from $2 \mathrm{~K}$ to $300 \mathrm{~K}$ indicating that they exist in an intermediate spin state $(S=1)$ up to room temperature.

For each of the complexes $1-4$ a value close to $\chi_{M} T=1.00 \mathrm{~cm}^{3} \mathrm{~K}$ $\mathrm{mol}^{-1}$ is observed across most of the measured range, with all complexes showing a slight upturn close to room temperature suggesting onset of a gradual thermal spin crossover. In the perchlorate complex 2 the $\chi_{M} T$ value starts to rise already by $110 \mathrm{~K}$ demonstrating the accessibility to the $\mathrm{S}=2$ state for $\mathrm{Mn}^{3+}$ in this coordination sphere. Below $20 \mathrm{~K}$ a characteristic drop is observed due to zero field splitting.

\section{High Field Electron Paramagnetic Resonance Spectra of 1}

Given the paucity of data on zero field splitting parameters in spin triplet $\mathrm{Mn}^{3+}$ complexes, ${ }^{31,36}$ it was of interest to record High Field EPR (HFEPR) spectra in order to investigate the nature of the anisotropy. Spectra were typically very weak in intensity so only complex 1 was studied in detail. Measurements were carried out on a powdered sample at $4.5 \mathrm{~K}$ and $10 \mathrm{~K}$ in the frequency range from 203 to $634 \mathrm{GHz}$. Representative spectra (along with simulations) recorded at frequencies of 406.4 and $203.2 \mathrm{GHz}$ are displayed in

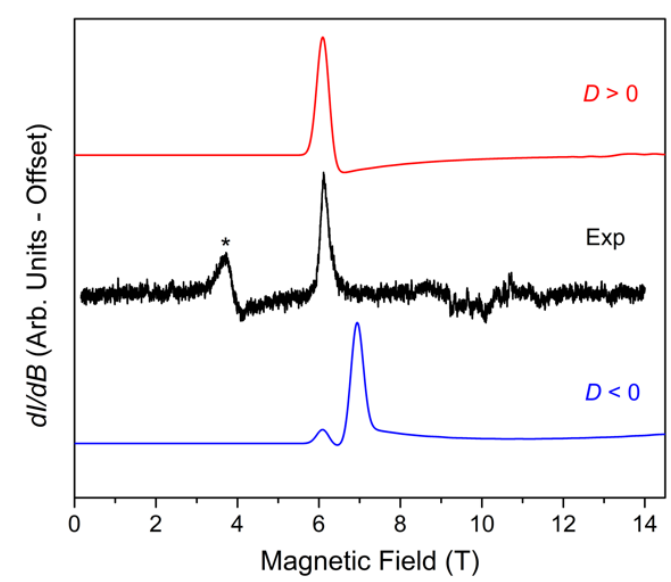

Figures 2 and S.2, respectively.

Figure 2. Powder EPR spectrum (recorded in derivative mode, $d I / d B$, where $I$ is the transmitted signal intensity) of 1 recorded at $4.5 \mathrm{~K}$ and $406.4 \mathrm{GHz}$ (black trace), along with spectral simulations assuming a powder distribution for the two crystallites, for both signs of $D$ (see text). * is trace impurity.

By plotting the observed resonance positions on a 2D magnetic field versus frequency plot, Figure 3 , it is found that most of them lie on a family of curves that can be well simulated according to a spin $S=1$ Hamiltonian given in the supporting information. The best simulation of the combined multi-frequency dataset places very tight constraints on the magnitudes of the axial and rhombic $2^{\text {nd }}$ order zero-field splitting parameters, $D$ and $E$. The sign of the dominant axial interaction can then be determined by comparing spectral simulations with the experimental ones for both signs of $D$. As can be seen from Figures 2 and S.2, a positive $D$ (red trace)

This journal is (C) The Royal Society of Chemistry 20xx 
accounts very well for several of the observed resonances, although not all of them; by contrast, a negative $D$ (blue trace) results in significant spectral features that are not observed experimentally. Therefore, the simulations unequivocally determine the sign of $D$ to be positive (the sign of $E$ remains undetermined). This was confirmed at other frequencies. The remaining resonances not captured by the $S=1$ simulations can either be attributed to known

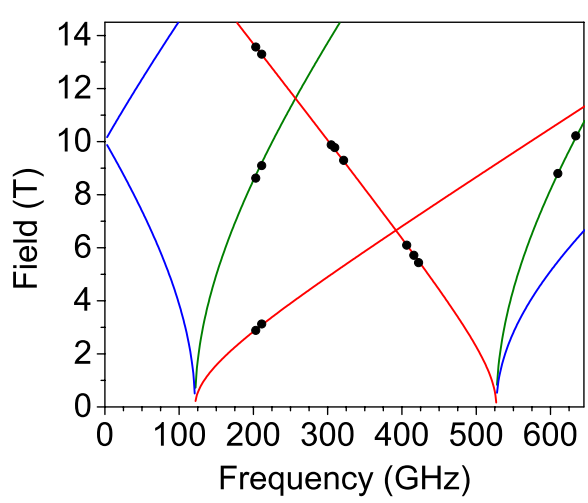

weak impurity signals in the EPR probe (see supporting information) or are assumed to be due to traces of the solvated complex.

Figure 3. 2D Magnetic field versus frequency (or quantum energy) map for $\mathbf{1}$ at $10 \mathrm{~K}$, where the experimental resonances are indicated with black points. The curves are simulations according to a $\mathrm{S}=1$ Hamiltonian (see $\mathrm{SI}$ ), with the colors denoting turning points in the powder spectra for field parallel to $x$ (green), $y$ (blue), $z$ (red).

Spin Hamiltonian parameters $D, E$ and $g$ were fitted to the multifrequency data, with the resulting values $D=+19.6 \mathrm{~cm}^{-1}$, = $2.02 \mathrm{~cm}^{-1}$ and $\mathrm{g}=2.00$. The zero field splitting parameters observed are in good agreement with those of the two $\mathrm{S}=1$ scorpionate $\mathrm{Mn}^{3+}$ complexes published by Forshaw et al., ${ }^{31}$ with reported $\mathrm{D}$ values of $+17.97 \mathrm{~cm}^{-1}$ and $+15.89 \mathrm{~cm}^{-1}$. This indicates that relatively large zero-field splitting can be expected in the spin triplet forms of $\mathrm{Mn}^{3+}$.

\section{Structural Characterisation of Unsolvated $(S=1)$ Complexes}

Single crystal X-ray diffraction at $100 \mathrm{~K}$ was used to characterise the structures of 1, 2 and 4 which agreed well with the powder diffraction data of the bulk samples, Figure S.15. The molecular structure of $\mathbf{1}$ is shown in Figure $\mathbf{4}$, and the structures of $\mathbf{2}$ and $\mathbf{4}$ are given in Figures S.3 and S.4 respectively. The asymmetric unit of complexes $\mathbf{1}$ and $\mathbf{4}$ comprises one full occupancy cation and one full occupancy anion while that for complex $\mathbf{2}$ comprises one half occupancy cation and one half occupancy anion, with a twofold rotational $\left(C_{2}\right)$ axis bisecting the pairs of cis-imine and cis-amine donors. In all cases the geometry around the $\mathrm{Mn}^{3+}$ centre is pseudooctahedral, with cis-amine, cis-imine and trans-phenolate donors. The $\mathrm{Mn}-\mathrm{O}$ and $\mathrm{Mn}-\mathrm{N}$ bond lengths, Table 2, correspond to expected $S=1$ values for related complexes. ${ }^{11-16}$ Octahedral distortion parameters $\Sigma$ and $\Theta$ are small and closely resemble the range of values previously reported for IS $(\mathrm{S}=1) \mathrm{Mn}^{3+15,38}$ Comparison of the packing interactions for the unsolvated complexes reveals a 1-D hydrogen bonding network which is common to $\mathbf{1}, \mathbf{2}$ and $\mathbf{4}$, in which the hydrogens of the amines of the complex cation form hydrogen bonds with bridging oxygens of the respective counter anion, Table S.6. This is illustrated for complex 1 in Figures 5 and S.6, and for complexes $\mathbf{2}$ and $\mathbf{4}$ in Figures S.8 and S.11.

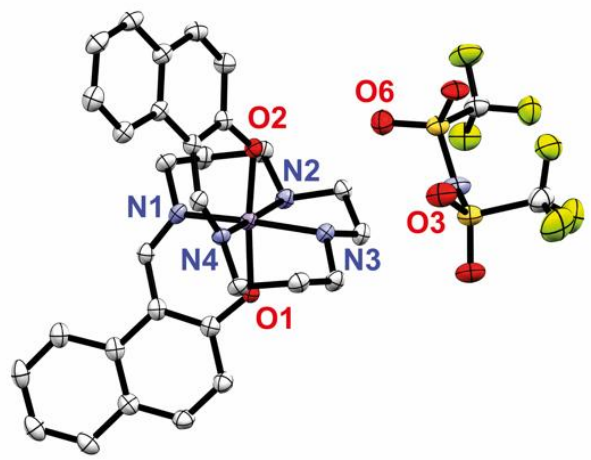

Figure 4. Structure of 1 recorded at $100 \mathrm{~K}$. Thermal ellipsoids are drawn at

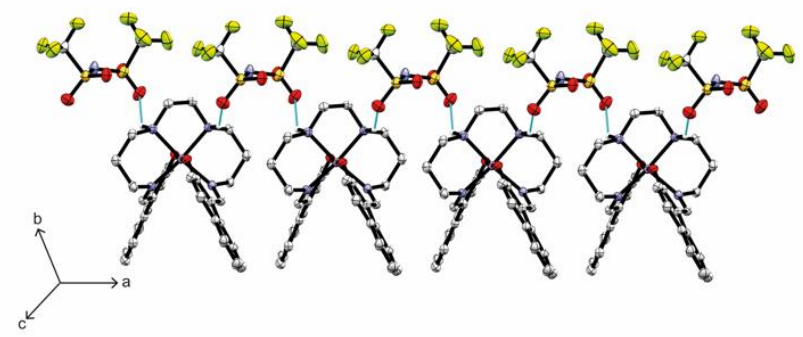

$50 \%$ atomic probability. Hydrogen atoms have been omitted for clarity

Figure 5. View of the 1-D hydrogen bonding network in 1. Thermal ellipsoids are drawn at $50 \%$ atomic probability. Hydrogen atoms, except those involved in the hydrogen bonding, have been omitted for clarity.

\section{Magnetic Characterisation of Solvated $(S=2)$ Complexes}

Given the thermal accessibility of the $S=2$ state in related complexes ${ }^{11-16}$ a natural progression would be to establish if the HS state of complexes $\mathbf{1}-\mathbf{4}$ could be stabilized by further crystal engineering. To this end the synthesis was repeated in a variety of solvents likely to promote extensive hydrogen bonding. Solvents mixtures included undried acetonitrile, ethanol and methanol. Attempts with methanol did yield crystals in some cases but the bulk products were of insufficient purity for further analysis. However attempts with ethanol yielded highly crystalline samples of [NA(rasd 323$)] C a 0.5\left(\mathrm{C}_{2} \mathrm{H}_{5} \mathrm{OH}\right)$, 20.5EtOH, and [Mrinas 323$)] \mathrm{B}_{4} 0.5\left(\mathrm{C}_{2} \mathrm{H}_{5} \mathrm{OH}\right), \mathbf{3 0 . 5 E t O H}$. SQUID data on the two solvated complexes shows that in contrast to the unsolvated analogues $\mathbf{2}$ and $\mathbf{3}$, they are fully HS over the measured temperature range 2-300 K, Figure 6 . The small upturn in the $\chi_{M} T$ data for 20.5EtOH may indicate ferromagnetic ordering at low temperatures but as the sample was not constrained it may also be 
due to torquing in the magnetic field on cooling. This may be due to the overall increased volume when ethanol is trapped in the lattice which could serve to push the complex cations apart so that they
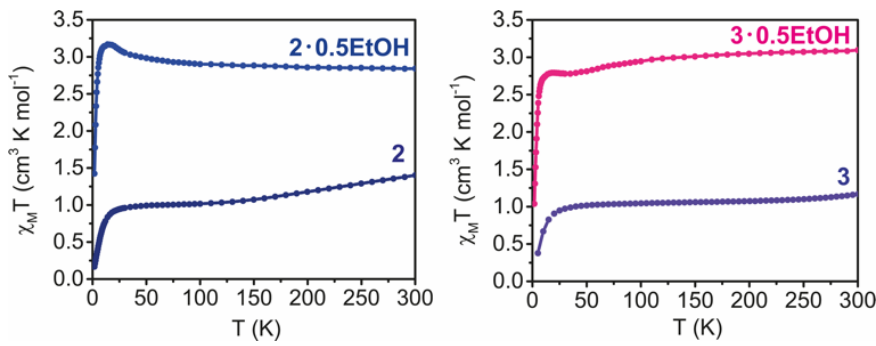

have more space to accommodate the longer $\mathrm{Mn}$-donor bonds which the $S=2$ state requires. The outcome is that incorporation of ethanol solvate molecules stabilizes the cation in the HS state, indicating that the spin state is highly sensitive to the lattice contents.

Figure 6. Plots of of $\chi_{M} T$ vs $T$ for complexes 2 and 2.0.5EtOH and 3 and 3.0.5EtOH from $5 \mathrm{~K}$ to $300 \mathrm{~K}$ illustrating the spin state dependence on lattice solvate molecules.

It is well known that anion ${ }^{40-42}$ and solvent ${ }^{12,17,43-47}$ affect choice of spin state in SCO complexes, in addition to the effects of local crystal field strength and geometry conferred by the ligand environment. Harding has recently demonstrated the importance of changing solvates in some $\mathrm{Fe}^{3+} \mathrm{SCO}$ complexes where significant differences in both profile and hysteresis width were observed. In the case of complexes $\mathbf{2}$ and $\mathbf{3}$ the effect of co-crystallizing solvent molecules is marked by a complete switch in spin state from triplet to quintet, opening the door to solvent-induced spin state changes in this cation.

\section{Structural Characterisation of the Solvated $(S=2)$ Complexes}

Single crystal $\mathrm{X}$-ray diffraction at $100 \mathrm{~K}$ was used to characterise the solvated complexes $2 \cdot 0.5 \mathrm{EtOH}$ and $3 \cdot 0.5 \mathrm{EtOH}$ which were found to

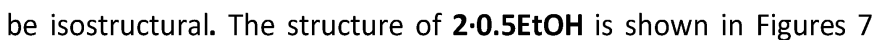
and S.4, and that of 3.0.5EtOH in Figure S.5. The asymmetric unit of each contains one full occupancy cation, one full occupancy anion and one half occupancy ethanol solvent molecule, which is disordered over two positions. In both cases, the geometry around the manganese centre is distorted octahedral, as expected in this pseudo Jahn-Teller ion. An expansion of the equatorial $\mathrm{Mn}-\mathrm{N}$ bonds is observed along with a slight compression of the $\mathrm{Mn}-\mathrm{O}$ bonds, Table 2. The octahedral distortion parameters $\Sigma$ and $\Theta$ are significantly larger than those of the $S=1$ unsolvated complexes, presumably due to the increased distortion in the HS state. Hydrogen bonding between the hydrogen of the amine on the ligand backbone and the oxygen of the counter anion is present but there is no chain formation for the interaction as was observed in the unsolvated $\mathbf{S}=1$ analogues $\mathbf{2}$ and $\mathbf{3}$. Instead the hydrogen bonding is discrete between one complex cation and one complex anion, Figures 8 and S.10. Weak offset $\pi-\pi$ interactions (3.67-3.74 $\AA$ ) between the naphthol rings are also observed which are just within the acceptable margins of $3.3-3.8 \AA^{39}{ }^{39}$ The packing of the

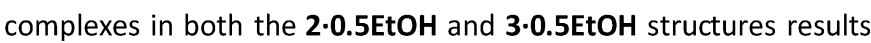
in channels containing the ethanol solvate parallel to the $a$ axis.

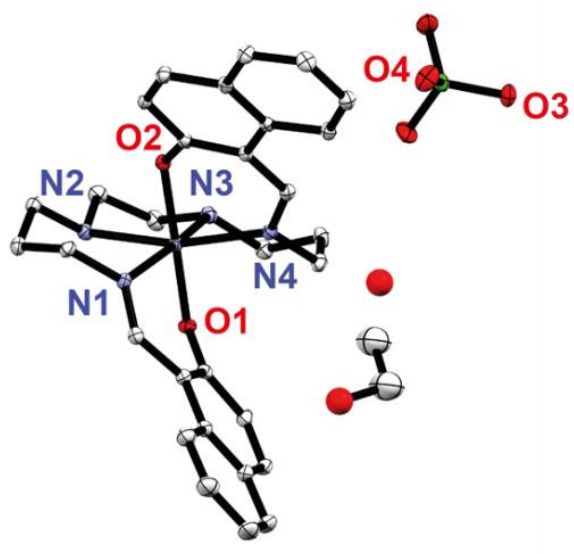

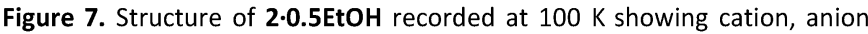
and disordered half-occupancy ethanol molecule. Thermal ellipsoids are drawn at $50 \%$ atomic probability. Hydrogen atoms have been omitted for clarity.

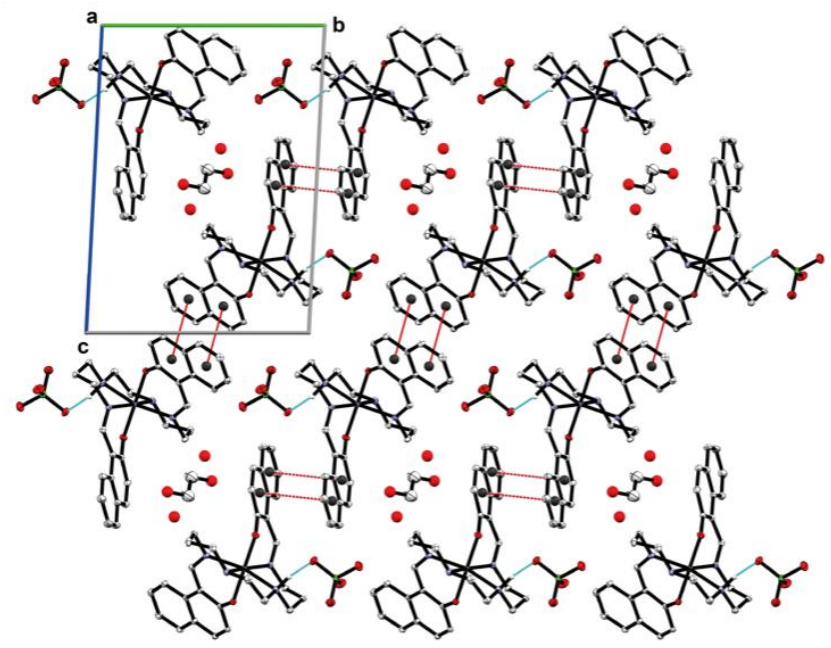

Figure 8. View of the intermolecular interactions in 2.0.5EtOH. Hydrogen bonding (b/ue) occurs between the hydrogen of the amine of the backbone and the oxygen atoms of the $\mathrm{ClO}_{4}^{-}$counter anion, and $\pi-\pi$ interactions (red) occur between the naphthol rings. See also Figure $\mathrm{S} .9$ and equivalent interactions for $\mathbf{3} \mathbf{0 . 5 E t O H}$ in Figure S.10. Thermal ellipsoids are drawn at $50 \%$ atomic probability. Hydrogen atoms, except those involved in the hydrogen bonding, have been omitted for clarity.

\section{Conclusions}

We have reported a new series of IS $(\mathrm{S}=1) \mathrm{Mn}^{3+}$ complexes of the $\left[\mathrm{Mn}\left(\text { napsal }{ }_{2} 323\right)\right]^{+}$cation. HFEPR measurements on the bistriflimide complex 1 to investigate the nature of the magnetic anisotropy 
yielded values of $D=+19.6 \mathrm{~cm}^{-1}$ and $\quad=2.02 \mathrm{~cm}^{-1}$, i.e. a large positive zero field splitting in line with previous reports on $S=1$ $\mathrm{Mn}^{3+}$ complexes. Structural information shows a strong 1-D hydrogen bonding network in the IS complexes 1, 2 and 4 . Cocrystallization with ethanol induced a complete change in spin state from $\mathrm{S}=1$ to $\mathrm{S}=2$ in the $\mathrm{ClO}_{4}^{-}$and $\mathrm{BF}_{4}^{-}$salts $2 \cdot 0.5 \mathrm{EtOH}$ and 3-0.5EtOH. The 1-D hydrogen bonding network is also broken in the solvated lattices, which may assist the change of spin state to the larger volume spin quintet form. Our work on studying the prevalence and stability of the $S=1$ state in this, and related complex cations, continues and will include investigation of the effect of different solvate molecules on the resultant $\mathrm{Mn}^{3+}$ spin state.

\section{Experimental}

\section{Synthetic Procedures}

\section{Synthesis of [Mn(napsal 2323$)] \mathrm{NTf}_{2}, 1$.}

2-Hydroxy-1-naphthaldehyde $(0.344 \mathrm{~g}, 2 \mathrm{mmol})$ was dissolved in acetonitrile $(10 \mathrm{~mL})$ and stirred for 10 minutes at room temperature. Neat 1,2-bis(3-aminopropylamino)ethane (165 $\mu \mathrm{L}, 1$ $\mathrm{mmol}$ ) was added to this solution and a bright yellow colour was immediately observed. The solution was filtered and manganese(II) chloride tetrahydrate $(0.197 \mathrm{~g}, 1 \mathrm{mmol})$ and neat triethylamine $(265$ $\mu \mathrm{L}, 2 \mathrm{mmol}$ ) were added, causing the colour to change to dark green. Solid lithium bis(trifluoromethanesulfonyl)imide $(0.287 \mathrm{~g}, 1$ $\mathrm{mmol}$ ) was added and the solution was stirred overnight. The dark green solution was then filtered and crystals suitable for X-ray crystallography were formed by slow evaporation of solvent. Yield: $0.080 \mathrm{~g} \quad(10 \%)$. Elemental Analysis, calculated for $\left[\mathrm{C}_{30} \mathrm{H}_{32} \mathrm{~N}_{4} \mathrm{O}_{2} \mathrm{Mn}\right]\left(\mathrm{CF}_{3} \mathrm{SO}_{2}\right)_{2} \mathrm{~N}$, Theory \% (Found \%): $\mathrm{C} 46.34$ (46.00), $\mathrm{H}$ 4.07 (3.73), N 8.44 (8.21).

Infrared Spectroscopy (FT-ATR) v/cm ${ }^{-1}: 3260$ (w), 3060 (w), 2960 (w), $2934(w), 2899(w), 2879(w), 1619(m), 1596(m), 1539(m)$, $1468(w), 1451(w), 1431(w), 1406(w), 1337(s), 1321(s), 1307(m)$, $1260(\mathrm{w}), 1225(\mathrm{~m}), 1184(\mathrm{~s}), 1129(\mathrm{~s}), 1084(\mathrm{~m}), 1054(\mathrm{~s}), 1009(\mathrm{~m})$ $991(\mathrm{~m}), 964(\mathrm{~m}), 948(\mathrm{~m}), 864(\mathrm{w}), 821(\mathrm{~s}), 791(\mathrm{~m}), 746(\mathrm{~s}), 654$ $(\mathrm{m}), 599(\mathrm{~s}), 570(\mathrm{~s}), 503(\mathrm{~s}), 466(\mathrm{~m}), 428(\mathrm{~m})$.

UV-Vis (MeCN) $\lambda_{\max } / \mathrm{nm}\left(\varepsilon_{\max } / \mathrm{mol} \mathrm{L}^{-1} \mathrm{~cm}^{-1}\right): 230.0(61,200), 307.4$ $(18,800), 540.5$ (970), 592.2 (780).

\section{Synthesis of $\left[\mathrm{Mn}\left(\right.\right.$ napsal $\left.\left._{2} 323\right)\right] \mathrm{ClO}_{4}, 2$.}

The procedure for 1 was repeated except sodium perchlorate $(0.122 \mathrm{~g}, 1 \mathrm{mmol})$ was used in place of the lithium bis(trifluoromethanesulfonyl)imide. Yield: $0.138 \mathrm{~g}(21 \%)$. Elemental Analysis, calculated for $\left[\mathrm{C}_{30} \mathrm{H}_{32} \mathrm{~N}_{4} \mathrm{O}_{2} \mathrm{Mn}\right] \mathrm{ClO}_{4}$, Theory \% (Found \%): $\mathrm{C}$ 56.75 (56.32), H 5.08 (4.90), N 8.82 (8.52).

Infrared Spectroscopy (FT-ATR) v/cm ${ }^{-1}: 3674(w), 3248$ (w), 2970 (w), $2929(w), 2901(w), 2866(w), 1623(s), 1596(m), 1545(m)$ $1470(\mathrm{~m}), 1441(\mathrm{~s}), 1386(\mathrm{~m}), 1343(\mathrm{w}), 1278(\mathrm{~s}), 1241(\mathrm{w}), 1207(\mathrm{w})$, $1150(\mathrm{w}), 1074(\mathrm{~s}), 1052(\mathrm{~s}), 986(\mathrm{~m}), 976(\mathrm{~m}), 933(\mathrm{~m}), 909(\mathrm{~m}), 866$ $(\mathrm{s}), 817(\mathrm{w}), 791(\mathrm{~m}), 768(\mathrm{~s}), 621(\mathrm{~s}), 564(\mathrm{~m}), 522(\mathrm{w}), 454(\mathrm{w}), 432$ (m).

UV-Vis (MeCN) $\lambda_{\max } / \mathrm{nm}\left(\varepsilon_{\max } / \mathrm{mol} \mathrm{L}^{-1} \mathrm{~cm}^{-1}\right): 230.0(68,200), 307.5$ $(20,800), 542.5(1,000), 592.4(860)$.

\section{Synthesis of $\left[\mathrm{Mn}\left(\right.\right.$ napsal $\left.\left._{2} 323\right)\right] \mathrm{BF}_{4}, 3$.}

The procedure for 1 was repeated except ammonium tetrafluoroborate $(0.104 \mathrm{~g}, 1 \mathrm{mmol})$ was used in place of the lithium bis(trifluoromethanesulfonyl)imide. Yield: $0.104 \mathrm{~g}(32 \%)$. Elemental Analysis, calculated for $\left[\mathrm{C}_{30} \mathrm{H}_{32} \mathrm{~N}_{4} \mathrm{O}_{2} \mathrm{Mn}_{\mathrm{B}} \mathrm{BF}_{4}\right.$, Theory \% (Found \%): C 57.90 (58.09), H 5.18 (5.23), N 9.00 (8.62).

Infrared Spectroscopy (FT-ATR) v/cm ${ }^{-1}: 3250$ (w), 2958 (w), 2929 $(w), 2911(w), 2866(w), 1614(m), 1594(s), 1537(m), 1504(m)$, $1449(\mathrm{~m}), 1431(\mathrm{~s}), 1392(\mathrm{~m}), 1358(\mathrm{~m}), 1339(\mathrm{~s}), 1305(\mathrm{~m}), 1258$ $(\mathrm{m}), 1194(\mathrm{~m}), 1121(\mathrm{w}), 1068(\mathrm{~s}), 1025(\mathrm{~s}), 1007(\mathrm{~s}), 991(\mathrm{~s}), 966(\mathrm{~s})$, $942(\mathrm{~m}), 911(\mathrm{w}), 862(\mathrm{w}), 825(\mathrm{~s}), 744(\mathrm{~s}), 648(\mathrm{w}), 605(\mathrm{~s}), 560(\mathrm{w})$, $515(\mathrm{~s}), 466(\mathrm{~m}), 432(\mathrm{w}), 420(\mathrm{w})$.

UV-Vis (MeCN) $\lambda_{\max } / \mathrm{nm}\left(\varepsilon_{\max } / \mathrm{mol} \mathrm{L}^{-1} \mathrm{~cm}^{-1}\right): 230.0(59,900), 307.8$ $(18,800), 540.4$ (520), 592.9 (420).

\section{Synthesis of $\left[\mathrm{Mn}\left(\right.\right.$ napsal $\left.\left._{2} 323\right)\right] \mathrm{NO}_{3}(4)$}

The procedure for 1 was repeated except manganese(II) nitrate tetrahydrate $(0.251 \mathrm{~g}, 1 \mathrm{mmol})$ was used in place of the manganese(II) chloride and lithium bis(trifluoromethanesulfonyl)imide. Yield: $0.090 \mathrm{~g}(15 \%)$. Elemental Analysis, calculated for $\left[\mathrm{C}_{30} \mathrm{H}_{32} \mathrm{~N}_{4} \mathrm{O}_{2} \mathrm{Mn} \mathrm{NO}_{3}\right.$, Theory \% (Found \%): C 60.30 (60.35), H 5.40 (5.70), N 11.72 (11.38).

Infrared Spectroscopy (FT-ATR) v/cm ${ }^{-1}: 3154$ (w), 2936 (w), 2909 (w), $2864(w), 1612(\mathrm{~m}), 1592(\mathrm{~s}), 1535$ (s), $1504(\mathrm{~m}), 1431$ (s), 1372 (s), 1325 (s), 1302 (s), 1254 (s), 1192 (s), 1145 (m), 1086 (s), 1031 $(\mathrm{s}), 995(\mathrm{~m}), 966(\mathrm{~m}), 907(\mathrm{w}), 864(\mathrm{~m}), 825(\mathrm{~s}), 748(\mathrm{~s}), 646(\mathrm{w}), 605$ $(\mathrm{s}), 556(\mathrm{~m}), 522(\mathrm{~s}), 469(\mathrm{~m}), 426(\mathrm{~m})$.

UV-Vis (MeCN) $\lambda_{\max } / \mathrm{nm}\left(\varepsilon_{\max } / \mathrm{mol} \mathrm{L}^{-1} \mathrm{~cm}^{-1}\right): 229.4(79,000), 304.3$ $(23,600), 540.8(1,200), 592.0(960)$.

\section{Synthesis of $\left[\mathrm{Mn}\left(\right.\right.$ napsal $\left.\left._{2} 323\right)\right] \mathrm{ClO}_{4} \cdot 0.5 \mathrm{EtOH}(2 \cdot 0.5 \mathrm{EtOH})$}

The procedure for 1 was repeated except sodium perchlorate $(0.122 \mathrm{~g}, 1 \mathrm{mmol})$ was used in place of the lithium bis(trifluoromethanesulfonyl)imide. Additionally, a 1:1 mixture of acetonitrile/ethanol was used instead of pure acetonitrile. Yield: $0.176 \mathrm{~g}$ (26\%). Elemental Analysis, calculated for $\left[\mathrm{C}_{30} \mathrm{H}_{32} \mathrm{~N}_{4} \mathrm{O}_{2} \mathrm{Mn}\right] \mathrm{ClO}_{4} \cdot 0.5\left(\mathrm{C}_{2} \mathrm{H}_{5} \mathrm{OH}\right.$ ), Theory \% (Found \%): C 56.58 (56.32), H 5.36 (4.97), N 8.51 (8.63).

Infrared Spectroscopy (FT-ATR) v/cm ${ }^{-1}: 3258$ (w), 2926 (w), 2866 $(w), 1617(m), 1602(s), 1545(m), 1506(w), 1451(m), 1409(w)$, $1360(\mathrm{w}), 1337(\mathrm{~m}), 1288(\mathrm{~m}), 1262(\mathrm{~m}), 1190(\mathrm{~m}), 1143(\mathrm{w}), 1078$ (s), $1058(\mathrm{~s}), 995(\mathrm{~m}), 944(\mathrm{~s}), 909(\mathrm{~m}), 858(\mathrm{~m}), 825(\mathrm{~s}), 778(\mathrm{w}), 750$ (s), $683(w), 646(w), 621(s), 605(s), 540(w), 501(m), 454(w), 418$ (m). 
UV-Vis (MeCN) $\lambda_{\max } / \mathrm{nm}\left(\varepsilon_{\max } / \mathrm{mol} \mathrm{L}^{-1} \mathrm{~cm}^{-1}\right): 230.2(72,100), 307.2$ $(22,200), 542.0(1,100), 592.2(870)$.

\section{Synthesis of $\left[\mathrm{Mn}\left(\right.\right.$ napsal $\left.\left._{2} 323\right)\right] \mathrm{BF}_{4} \cdot 0.5 \mathrm{EtOH}(3 \cdot 0.5 \mathrm{EtOH})$}

The procedure for 1 was repeated except ammonium tetrafluoroborate $(0.104 \mathrm{~g}, 1 \mathrm{mmol})$ was used in place of the lithium bis(trifluoromethanesulfonyl)imide. Additionally, a 1:1 mixture of acetonitrile/ethanol was used instead of pure acetonitrile. Yield: $0.078 \mathrm{~g}$ (12\%). Elemental Analysis, calculated for $\left[\mathrm{C}_{30} \mathrm{H}_{32} \mathrm{~N}_{4} \mathrm{O}_{2} \mathrm{Mn}\right] \mathrm{BF}_{4} \cdot 0.5\left(\mathrm{C}_{2} \mathrm{H}_{5} \mathrm{OH}\right.$ ), Theory \% (Found \%): C 57.69 (57.77), H 5.47 (5.36), N 8.68 (8.59).

Infrared Spectroscopy (FT-ATR) v/cm ${ }^{-1}: 3356.2$ (w), 3256.3 (w), 3056.5 (w), 2960.7 (w), 2919.9 (w), 2866.9 (w), 1616.9 (m), 1594.5 $(\mathrm{s}), 1539.5(\mathrm{~s}), 1504.8(\mathrm{~m}), 1464.0(\mathrm{w}), 1449.7(\mathrm{~m}), 1431.4(\mathrm{~s})$, $1390.6(\mathrm{~m}), 1358.0(\mathrm{w}), 1339.6(\mathrm{~s}), 1302.9(\mathrm{~s}), 1260.1(\mathrm{~m}), 1213.2$ $(w), 1194.9(\mathrm{~m}), 1158.2(\mathrm{w}), 1143.9(\mathrm{~m}), 1125.5(\mathrm{w}), 1088.8(\mathrm{~s})$, $1078.6(\mathrm{~s}), 1052.1(\mathrm{~s}), 1035.8(\mathrm{~s}), 993.0(\mathrm{~m}), 944.1(\mathrm{w}), 876.8(\mathrm{~m})$, $862.5(\mathrm{~m}), 825.8(\mathrm{~s}), 748.3(\mathrm{~s}), 646.4(\mathrm{w}), 605.6(\mathrm{~s}), 558.7(\mathrm{w}), 515.9$ $(m), 483.2(w), 466.9(w), 422.1(m)$.

UV-Vis (MeCN) $\lambda_{\max } / \mathrm{nm}\left(\varepsilon_{\max } / \mathrm{mol} \mathrm{L}^{-1} \mathrm{~cm}^{-1}\right): 230.0(78,300), 307.0$ $(24,200), 541.0(1,200), 592.9$ (900).

\section{Conflicts of interest}

\section{Therearerocoflidstodetare}

\section{Acknowledgements}

We thank Science Foundation Ireland (SFI) for generous support of an Investigator Project Award (12/IP/1703 to G.G.M). This research was also supported by the Irish Research Council GOIPG/2018/2510 (C.T.K.), GOIPG/2015/2713 (P.W.), GOIPD/2016/503 (I.A.K.), US Department of Energy DE-SC0019330 (S.H.), EU COST Actions CA15128 Molecular Spintronics (MOLSPIN), CM1305, Explicit Control over Spin-states in Technology and Biochemistry (ECOSTBio) and CA15107 Multi-Functional Nano-Carbon Composite Materials Network (MultiComp). We also thank University College Dublin (UCD) for their generous support via award of a UCD Advance PhD Supplemental Funding Grant (C.T.K. and G.G.M.). A portion of this work was performed at the National High Magnetic Field Laboratory, which is supported by the National Science Foundation Cooperative Agreement No. DMR-1644779 and the State of Florida. This work was also supported through award of an RSC Research Mobility Grant from the Royal Society of Chemistry (RSC) (I.A.K.).

\section{Notes and references}

1. H. Song, M. A. Reed and T. Lee, Adv. Mater., 2011, 23, 15831608.

2. K. Senthil Kumar and M. Ruben, Coord. Chem. Rev., 2017, 346, 176-205.
3. S.K. Kuppusamy, B. Heinrich, J. Arabski, G. Schmerber,M. Bowen, S. Boukari, E. Beaurepaire, J. Dreiser, M. Ruben, Adv. Mater. 2018, 1705416.

\section{O. Kahn and C. J. Martinez, Science, 1998, 279, 44-48.}

5. F. Schleicher, M. Studniarek, S.K. Kuppusamy, E. Urbain,K. Katcko, J. Chen,T. Frauhammer, M. Herve', U. Halisdemir, L.M.Kandpal, D. Lacour, A. Riminucci, L.Joly, F. Scheurer, B. Gobaut, F. Choueikani, E. Otero, P. Ohresser, J. Arabski, G. Schmerber, W. Wulfhekel, E. Beaurepaire, W.Weber, S. Boukari, M. Ruben, M. Bowen,ACS Appl. Mater. Interfaces. 2018, 10, 31580-31585.

6. S. Mossin, B. L. Tran, D. Adhikari, M. Pink, F. W. Heinemann, J. Sutter, R. K. Szilagyi, K. Meyer, D. J. Mindiola, J. Am. Chem. Soc., 2012, 134, 13651-13661.

7. W. O. Koch, V. Schünemann, M. Gerdan,A. X. Trautwein, H. -J. Krüger, Chem. Eur. J., 1998, 4, 686-691.

8. M. G. Cowan, J. Olguín, S. Narayanaswamy, J. L. Tallon and S. Brooker, J. Am. Chem. Soc., 2011, 134, 2892-2894.

9. S. Hayami, K. Murata, D. Urakami, Y. Kojima, M. Akita and K. Inoue, Chem. Commun., 2008, 0, 6510-6512.

10. P. G. Sim and E. Sinn, J. Am. Chem. Soc., 1981, 103, 241-243.

11. G. G. Morgan, K. D. Murnaghan, H. Müller-Bunz, V. McKee and C. J. Harding, Angew. Chem., Int. Ed., 2006, 45, 7192-7195.

12. K. Pandurangan, B. Gildea, C. Murray, C. J. Harding, H. MüllerBunz and G. G. Morgan, Chem. Eur. J., 2012, 18, 2021-2029.

13. A. J. Fitzpatrick, E. Trzop, H. Müller-Bunz, M. M. Dîrtu, Y. Garcia, E. Collet and G. G. Morgan, Chem. Commun., 2015, 51, 1754017543.

14. P. N. Martinho, B. Gildea, M. M. Harris, T. Lemma, A. D. Naik, H. Müller-Bunz, T. E. Keyes, Y. Garcia and G. G. Morgan, Angew. Chem. Int. Ed., 2012, 51, 12597-12601.

15. B. Gildea, M. M. Harris, L. C. Gavin, C. A. Murray, Y. Ortin, H. Müller-Bunz, C. J. Harding, Y. Lan, A. K. Powell and G. G. Morgan, Inorg. Chem., 2014, 53, 6022-6033.

16. B. Gildea, L. C. Gavin, C. A. Murray, H. Müller-Bunz, C. J. Harding, and G. G. Morgan, Supramol. Chem., 2012, 24, 641-653.

17. J. Sirirak, D. J. Harding, P. Harding, K. S. Murray, B. Moubaraki, L. Liu and S. G. Telfer, Eur. J. Inorg. Chem., 2015, 2015, 2534-2542.

18. Z. Liu, S. Liang, X. Di and J. Zhang, Inorg. Chem. Commun., 2008, 11, 783-786.

19. S. Wang, M. Ferbinteanu, C. Marinescu, A. Dobrinescu, Q.-D. Ling and W. Huang, Inorg. Chem., 2010, 49, 9839-9851.

20. R. F. Ziolo, R. H. Stanford, G. R. Rossman and H. B. Gray, J. Am. Chem. Soc., 1974, 96, 7910-7915. 
21. J. J. Alexander and H. B. Gray, J. Am. Chem. Soc., 1968, 90, 4260-4271.

22. I. D. Chawla and M. J. Frank, J. Inorg. Nucl. Chem., 1970, 32, 555-563.

23. W. P. Griffith, Coord. Chem. Rev., 1975, 17, 177-247.

24. W. E. Buschmann, L. Liable-Sands, A. L. Rheingold and J. S. Miller, Inorganica Chim. Acta, 1999, 284, 175-179.

25. H. Homborg, L. Galich and H. Hu, J. Porphyr. Phthalocyanines, 1998, 2, 79-87.

26. J. T. Landrum, K. Hatano, W. Robert Scheldt and C. A. Reed, J. Am. Chem. Soc., 1980, 102, 6729-6735.

27. A. P. Hansen and H. M. Goff, Inorg. Chem., 1984, 23, 45194525.

28. M. Matsuda, J.-I. Yamaura, H. Tajima and T. Inabe, Chem. Lett., 2005, 34, 1524-1525.

29. S. Mossin, H. O. Sørensen and H. Weihe, Acta Crystallogr. Sect. C Cryst. Struct. Commun., 2002, 58, m204-m206.

30. H. E. Colmer, C. G. Margarit, J. M. Smith, T. A. Jackson and J. Telser, Eur. J. Inorg. Chem., 2016, 2016, 2413-2423.

31. A. P. Forshaw, J. M. Smith, A. Ozarowski, J. Krzystek, D. Smirnov, S. A. Zvyagin, T. D. Harris, H. I. Karunadasa, J. M. Zadrozny, A. Schnegg, K. Holldack, T. A. Jackson, A. Alamiri, D. M. Barnes and J. Telser, Inorg. Chem., 2013, 52, 144-159.

32. F. Hossain, M. A. Rigsby, C. T. Duncan, P. L. Milligan, R. L. Lord, M. Baik and F. A. Schultz, Inorg. Chem., 2007, 46, 2596-2603.

33. D. C. L. De Alwis and F. A. Schultz, Inorg. Chem., 2003, 42, 36163622.

34. P. Basu and A. Chakravorty, Inorg. Chem., 1992, 31, 4980-4986.

35. S. Ganguly, S. Karmakar and A. Chakravorty, Inorg. Chem., 1997, 36, 116-118.

36. C. Duboc, Chem. Soc. Rev., 2016, 45, 5834-5847.

37. J. Krzystek, A. Ozarowski and J. Telser, Coord. Chem. Rev., 2006, 250, 2308-2324.

38. A. J. Fitzpatrick, S. Stepanovic, H. Müller-Bunz, M. A. GrudenPavlović, P. García-Fernández and G. G. Morgan, DaltonTrans., 2016, 45, 6702-6708.

39. C. Janiak, Dalton Trans., 2000, 3885-3896.

40. S. Sundaresan, I. A. Kühne, C. T. Kelly, A. Barker, D. Salley, H. Müller-Bunz, A. K. Powell, G. G. Morgan, S. Sundaresan, I. A. Kühne, C. T. Kelly, A. Barker, D. Salley, H. Müller-Bunz, A. K. Powell and G. G. Morgan, Crystals, 2018, 9, 19.
41. S. Hayami, K. Hiki, T. Kawahara, Y. Maeda, D. Urakami, K. Inoue, M. Ohama, S. Kawata and O. Sato, Chem. Eur. J., 2009, 15, 34973508.

42. I. Nemec, R. Herchel, R. Boĉa, Z. Trávnícek, I. Svoboda, H. Fuess and W. Linert, Dalton Trans., 2011, 40, 10090-10099.

43. D. Sertphon, P. Harding, K. Murray, B. Moubaraki, S. Neville, L. Liu, S. Telfer and D. Harding, Crystals, 2019, 9, 116.

44. A. Malliaris and V. Papaefthimiou, Inorg. Chem., 1982, 21, 770774.

45. I. A. Gass, S. Tewary, G. Rajaraman, M. Asadi, D. W. Lupton, B. Moubaraki, G. Chastanet, J.-F. Létard and K. S. Murray, Inorg. Chem., 2014, 53, 5055-5066.

46. M. Hostettler, K. W. Törnroos, D. Chernyshov, B. Vangdal and H.-B. Bürgi, Angew. Chem. Int. Ed., 2004, 43, 4589-4594.

47. W. Phonsri, P. Harding, L. Liu, S. G. Telfer, K. S. Murray, B. Moubaraki, T. M. Ross, G. N. L. Jameson and D. J. Harding, Chem. Sci., 2017, 8, 3949-3959. 
Table 2. Selected bond lengths ( $(\AA)$ and distortion parameters $\left({ }^{\circ}\right)$ for $1,2,2 \cdot 0.5 \mathrm{EtOH}, 3 \cdot 0.5 \mathrm{EtOH}$, and 4

\begin{tabular}{|c|c|c|c|c|c|c|}
\hline Complex & 1 & 2 & 4 & 5 & 2.0.5EtOH & 3.0.5EtOH \\
\hline$M n-O(1)$ & $1.8753(19)$ & $1.8855(14)$ & $1.8762(8)$ & $1.8687(13)$ & $1.8679(10)$ & $1.8671(10)$ \\
\hline$M n-O(2)$ & $1.870(2)$ & & $1.8803(8)$ & $1.8764(13)$ & $1.8635(10)$ & $1.8701(10)$ \\
\hline$M n-N(1)_{\text {imine }}$ & $1.975(2)$ & $1.9946(17)$ & $1.9876(11)$ & $1.9814(16)$ & $2.0846(12)$ & $2.1211(11)$ \\
\hline$M n-N(4)_{\text {imine }}$ & $1.978(2)$ & & $1.9825(10)$ & $1.9805(16)$ & $2.1143(13)$ & $2.0872(12)$ \\
\hline $\mathrm{Mn}-\mathrm{N}(2)_{\text {amine }}$ & $2.063(2)$ & $2.0630(17)$ & $2.0548(10)$ & $2.0654(17)$ & $2.2381(13)$ & $2.2398(12)$ \\
\hline $\mathrm{Mn}-\mathrm{N}(3)_{\text {amine }}$ & $2.058(2)$ & & $2.0573(10)$ & $2.0643(17)$ & $2.2429(13)$ & $2.2426(11)$ \\
\hline$\Sigma$ & 35.32 & 30.97 & 31.27 & 34.34 & 71.37 & 71.25 \\
\hline$\theta$ & 97.20 & 97.07 & 88.41 & 96.48 & 238.81 & 239.22 \\
\hline
\end{tabular}

